\title{
CENÁRIO EMPRESARIAL PÓS PANDEMIA: O ESTRATÉGICO E O OPERACIONAL
}

\section{POST-PANDEMIC BUSINESS SCENARIO: THE STRATEGIC AND THE OPERATIONAL}

Wallace Gomes Moraes,

Graduado em Administração (UPIS), Graduado em Tecnologia do Cooperativismo (UFV), Especialização em Administração Rural (UFLA), Especialização em Gerenciamento de Resíduos da Agroindústria (UFLA),

Professor do Curso de Administração da Faculdade Presidente Antônio Carlos de Teófilo Otoni, Brasil. E-mail: moraes.wallace@bol.com.br

Marcélia Aguiar Ferreira, Mestre em Administração Pública pela Universidade Federal dos Vales do Jequitinhonha e Mucuri, Especialista em Comunicação, Marketing e RH pela, Pós Graduada em Docência do Ensino Superior, Graduada em Administração, Coordenadora dos Cursos de Administração e Ciências Contábeis e Coordenadora Adjunta do Curso de Sistemas de Informação da UNIPAC Teófilo Otoni, Brasil. E-mail: marceliaaguiar@hotmail.com

Thiago Ribeiro Oliveira, Mestre em Tecnologia, Ambiente e Sociedade, Especialista em Gestão Pública Municipal, Bacharel em Ciências Contábeis. Professor do curso de Contábeis da Faculdade Presidente Antônio Carlos de Teófilo Otoni, Brasil. E-mail: thiagoribeirounipac@gmail.com

Recebido: 10/11/2020 - Aceito: 27/11/2020

\section{Resumo}

Inegavelmente a pandemia pelo Covid-19 irá determinar um marco divisor no ambiente corporativo. A pandemia conferiu muita nebulosidade ao processo de tomada de decisão criando um cenário de incertezas quanto ao rumo que a economia tomará daqui para frente. Nem mesmo a Revolução Industrial ocorrida na Europa, nos séculos XVIII e XIX, ocasionou um grau de incerteza econômica tão grande para as empresas e, consequentemente para a sociedade, quanto esta pandemia. Diante deste quadro já se vislumbra uma série de modificações no ambiente empresarial no sentido de minimizar os efeitos colaterais desta pandemia. Neste processo de transformação as empresas necessitarão de buscar amparo nas informações como ponto basilar no processo decisório 
estratégico. Além das informações as empresas terão também que se adequarem a um mundo extremamente digital que irá impor mudanças estruturais e comportamentais dentro das organizações, com uma velocidade exponencial. Aquelas que conseguirem se adaptar terão maiores chances de sobreviver e até auferir vantagens que antes não dispunham. É, pois, um momento de mudança e a palavra de ordem será adaptação ao novo cenário, que não retornará ao que era antes.

Palavras Chaves: Mudanças; Informações; Ambiente digital; Processo Decisório.

\section{ABSTRACT}

Undoubtedly, the Covid-19 pandemic will set a milestone in the corporate environment. The pandemic added a lot of cloudiness to the decision-making process, creating a scenario of uncertainty as to the direction the economy will take from now on. Not even the Industrial Revolution that occurred in Europe, in the 18th and 19th centuries, caused such a degree of economic uncertainty for companies and, consequently, for society, as this pandemic. In view of this situation, a series of changes in the business environment are already envisaged in order to minimize the side effects of this pandemic. In this transformation process, companies will need to seek support from information as a basic point in the strategic decision-making process. In addition to information, companies will also have to adapt to an extremely digital world that will impose structural and behavioral changes within organizations, with exponential speed. Those that manage to adapt will have a better chance of surviving and even gaining advantages that they did not have before. It is, therefore, a moment of change and the watchword will be adaptation to the new scenario, which will not return to what it was before.

Keywords: Changes, Information; Digital environment; Decision-making process.

\section{1-Introdução}

Seja qual for o segmento econômico e com a visão mais otimista o cenário pós pandemia irá trazer em seu bojo significativas mudanças no ambiente corporativo em todas a suas áreas, traduzindo-se em experiências novas em termos estruturais e comportamentais. Nada será como antes nos processos estratégicos e operacionais. Novos conceitos aparecerão para fazer face às novas exigências de mercado.

Mudanças estruturais nos processos de compras, de produção, de vendas e nas formas de interelacionamento humano, certamente irão significar quebras de paradigmas. 
As empresas terão a missão de se reinventarem tornando-se mais ágeis e proativas, no sentido de criarem novos conceitos e novas metodologias, para obterem competividade em um mercado globalizado e altamente interdependente.

As informações nunca foram tão importantes neste cenário e, portanto, saber administra-las passará a ser algo de incontestável valor. As empresas irão operar num mundo virtual que será ágil, volátil e extremamente desafiador.

Novas ferramentas digitais passarão a ser incorporadas rotineiramente pelas empresas no sentido de facilitar o processo decisório. 0 surgimento de novas tecnologias aliadas a uma enorme concorrência no mercado será fundamental no processo operacional e na sua competitividade e longevidade. Fato é que, as mudanças que ocorreram no mundo pós-pandemia serão muito rápidas. A dificuldade em delinear como será o futuro, esbarra na quantidade de variáveis envolvidas, o que torna difícil qualquer exercício de futurologia.

\section{2- Administrando informações}

Diante deste cenário extremamente, incerto e conturbado, as informações serão de grande valia para as organizações. O cenário econômico passando por enormes turbulências terá que buscar apoio nas informações globalizadas e interdependentes.

Peter Drucker (1992) já se posicionava que elas interferiam de tal forma em nossas vidas que elas já se posicionariam juntamente com os tradicionais fatores de produção: terra, trabalho e capital, como um fator que pode propiciar e garantir as vantagens competitivas de uma empresa.

Fica embutido aí o entendimento que as empresas devem estar abertas a possíveis mudanças e para tanto serem flexíveis, visto que a eficácia no tratamento de uma informação delimita uma linha tênue entre ela ser positiva ou negativa.

Segundo Moraes (2012) considerando que as informações estão altamente massificadas e democratizadas e sendo veiculadas em tempo real, é importante ter o senso crítico e avaliativo para entender que estas informações 
guardam em seu bojo aspectos tanto positivos quanto negativos e que o grande diferencial passa a ser saber usá-las de forma a se tornarem vantagens competitivas.

Como o processo decisório envolvendo as atividades de uma empresa tem por base algum tipo de informação, será fundamental para as empresas obterem informações de forma rápida, confiável e no momento certo, para serem usadas de forma eficiente, pois até mesmo as informações valiosas podem ser desperdiçadas pelo simples fato de não serem bem processadas.

Moraes (2012) diz que a informação sempre esteve presente nas organizações, porém, com a evolução do ambiente corporativo, seu volume e valor aumentaram muito, exigindo uma solução para seu tratamento. Por isso, as organizações têm procurado um uso cada vez mais intenso e amplo dos sistemas de informação, visto que eles se tornaram um componente crítico do planejamento estratégico corporativo e de vantagem competitiva.

A vantagem competitiva, advinda do uso adequado das informações, não pode ficar restrita a uma aplicação específica, mas sim a um processo contínuo de planejamento e implantação de sistemas eficazes, já que as organizações estão atualmente enfrentando um mercado competitivo, globalizado e turbulento, e por isso mesmo, necessitam de informações oportunas e conhecimentos personalizados, para efetivamente auxiliar no processo decisório

Empresas que sabem usar a informação disponível são inevitavelmente aquelas que têm melhor desempenho, pincipalmente aquelas que forem usadas de forma estratégica. Relegar as informações, por mais simplórias que pareçam, podem resultar em pontos de gargalos futuros.

As informações são estáticas e inertes. O que transforma a informação em atitude ou ato terá sempre a interveniência do homem, através do processo decisório pessoal. Esta característica intrínseca de uma informação confere a quem fizer uso, dispor de livre arbítrio para poder utilizá-la ou não, no momento atual ou futuro. Logo, em decorrência desses requisitos, as empresas devem estar sempre atualizadas em relação à sua visão estratégica, sempre atentas às mudanças, evitando decisões erradas que possam comprometer o desempenho empresarial. 
A grande dicotomia no cenário atual, segundo Moraes (2012) é dispor de informação demais sem saber como usá-la. É como sentir-se solitário em uma multidão. É fundamental que se tenha um conhecimento prévio do assunto, caso contrário, não se tem o que fazer com a informação. Pouco conhecimento ou uma forma errônea de conhecimento é pior do que nenhum conhecimento, pois isto induz a percepção de que se sabe e passa a ser o arauto do erro. Saber escolher e priorizar as informações passa ser talvez o grande diferencial dos gestores.

\section{3- Administrando tecnologias}

O surgimento de novas tecnologias aliada a uma enorme velocidade de lançamento e muita concorrência entre os fabricantes têm imprimido à área tecnológica, dentro das organizações, uma importância inegável tanto na sua operacionalização, quanto na sua estratégia competitiva.

Atualmente, a utilização das ferramentas tecnológicas como arma competitiva tem recebido grande atenção por parte das organizações. Dada esta visão da importância estratégica que essas ferramentas representam para as empresas a preocupação essencialmente técnica do seu avanço tem aberto espaço, para uma preocupação com a administração da disponibilidade e diversidade tecnológicas, atuais e futuras, alinhando-as com as estratégias organizacionais.

Os sistemas informatizados devem ser entendidos como ferramentas auxiliares no processo de gestão e não uma panaceia para a resolução dos problemas. A lei do menor esforço não pode imperar frente ao contexto maior. Culpar o sistema ou a falta dele é alienar-se diante da tecnologia, que em suma, foi criada para atender e auxiliar o homem. Ela não pode ser guindada a planos superiores a ponto de interferir no processo decisório.

É ponto pacífico que as empresas devem buscar informações sobre as novidades tecnológicas, como são utilizadas, quais os benefícios podem trazer e verificar a possibilidade de adequação à sua necessidade.

Neste aspecto há que se considerar que a área tecnológica dentro do ambiente corporativo não deve apenas considerar os aspectos técnicos de sua função, mas também os sociais, voltados para o relacionamento entre as 
pessoas e os seus atributos, tais como atitudes, competências e valores, considerando tanto seu ambiente interno quanto o externo, responsabilizando pela garantia do perfeito relacionamento da função com a organização e, apoiar esta última, na sua operacionalização e estratégia competitiva.

É importante desmistificar que somente as grandes empresas podem utilizar de tecnologias. Empresas de qualquer porte e em qualquer lugar podem e devem buscar no uso de tecnologias instrumentos poderosos de gestão administrativa, já que agilizam os processos de negócios

Fica patente que investir em tecnologia permite angariar resultados positivos que vão desde a expansão de mercado, melhor relacionamento como os clientes e fornecedores, redução de custos, aumento do nicho de mercado, até a criação de uma cultura de conhecimento coletivo, evitando assim duplicidade de informação e clareza de propósitos.

Os irmãos Polo em seu livro Socialholic adotam um conceito novo de consumidor que segundo eles, está mais antenado e conectado com o mundo, ligado à atualidade, com muita vontade de compartilhar as coisas e que encontrou a tecnologia como aliada. Segundo eles o consumidor ganha poder e "agora as marcas não têm mais desculpa para não escutar os clientes e agir". Essa é uma nova filosofia, na qual é importante "interagir com os usuários". É preciso começar a investir na relação com os clientes".

Segundo Moraes (2012) à medida que estas mídias vão se socializando são quebrados paradigmas de descrédito e desconfiança e a interelação tende a ser mais amena e menos conflituosa entre os clientes e a empresa. O mundo embora virtual tende a ser mais perceptível e real, pela proximidade e informalidade com que as informações e a comunicação se processam.

Torres (2009) define as mídias sociais como:

Sites na Internet que permitem a criação e o compartilhamento de informações e conteúdos pelas pessoas e para as pessoas, nas quais o consumidor é ao mesmo tempo produtor e consumidor da informação. Elas recebem esse nome porque são sociais, ou seja, são livres e abertas à colaboração e interação de todos, e porque são 
mídias, ou seja, meios de transmissão de informações e conteúdo.

Sendo assim, as mídias sociais possibilitam a discussão e a troca de informação entre indivíduos e organizações presentes na internet, promovendo também de forma aberta, a conectividade e a troca de experiências entre as próprias pessoas, possibilitando a interação estável e contínua entre esses indivíduos.

De acordo com. (Kotler, Hermawan e Setiawan, 2017), a expansão da mídia social que ignora quaisquer barreiras, possibilita que os consumidores expressem seus pontos de vista e opiniões sobre as marcas, aguçando cada vez mais a desconfiança sobre o velho marketing usado por elas, e confiando mais nas avaliações presentes nas mídias sociais, e buscando nelas, conselhos e recomendações para a tomada de decisão. Portanto, o processo de compra acaba sofrendo grande influência e se tornando mais compartilhado e globalizado.

Assim, as mídias sociais se tornaram fontes repletas de informações que são usadas e também alimentadas pelos próprios consumidores, de forma rápida e fácil, não havendo um controle sobre o que se pública ou compartilha.

De acordo com Kotler e Armstrong (2003)

O consumidor moderno busca constantemente novos produtos e serviços, nesse sentido, é preciso que a organizações acompanhem as mudanças desse novo mercado e ofereçam um atendimento de qualidade, causando satisfação aos clientes e se fortalecendo perante a concorrência.

Segundo a avaliação do diretor executivo da Infobase e coordenador do MBA em marketing, inteligência de negócios digitais da Fundação Getúlio Vargas (FGV), André Miceli, que realizou o estudo Tendências de Marketing e Tecnologia 2020: Humanidade Redefinida e os Novos Negócios, durante muito tempo, a tecnologia estava associada à desumanização, a criar distância entre as pessoas, as pessoas pararam de se olhar e passaram só a digitar umas com 
as outras, passaram a conversar menos, que tem mil amigos no Facebook mas nenhum amigo na vida real".

Ainda segundo André Miceli torna-se fundamental que as empresas entendam que a tecnologia é, cada vez mais, um ativo humano. Nesse momento de isolamento, observa-se que a tecnologia é uma grande ferramenta de humanização quando ela é usada dessa forma. A sociedade está aprendendo a ressignificar o uso que dá para a tecnologia".

Em muitos setores, segundo André Miceli o fator tecnológico faz com que o conhecimento adquirido tenha prazo de validade curto. O que se sabe hoje perde valor ao longo do tempo, à medida que novas e inovadoras tecnologias disruptivas vão surgindo.

Em seus estudos Miceli pontua que a dificuldade em absorvermos certas previsões futuristas, e delinearmos um mundo pós-pandemia, é que, embora a tecnologia evolua de forma exponencial, nosso pensamento intuitivo é linear. Assim, olhamos a evolução do século passado e projetamos mudanças para os próximos 100 anos baseados na linearidade do nosso modelo mental.

\section{4- Ambiente corporativo pós pandemia}

Sem dúvida a pandemia pelo corona vírus passa a ser um divisor de águas no que se refere à forma com as estruturas organizacionais se posicionam no mercado.

Segundo Cezar Taurion (2016) conceitos tradicionais embasados na estrutura hierárquica, matricial e gerenciada de forma top-down (comando e controle), direcionada por resultados financeiros de curto prazo, planejamento estratégico baseado na extrapolação linear do passado, avessa à riscos, inflexível nos processos e mudanças organizacionais, grande número de funcionários, terão que ser revistos.

Inevitavelmente o ambiente de negócios terá que ser repensado tal forma como aconteceu com o advento pós Internet. Por mais que os futuristas tentem entender o mundo pós Covit-19, em toda a sua amplitude, fica quase impossível imaginar o que vem pela frente. 
Possivelmente a empresa pós-Covid será uma empresa onde as pessoas poderão trabalhar de onde for necessário criando novos ambientes laborais. Embora o mundo presencial não seja necessário ele deixa de ser uma obrigação. Consequentemente, as legislações, normas e os processos organizacionais e de gestão terão que ser mudados.

Salim Ismail e Yuri van Geest, em seu livro "Exponential Organizations" enfatiza que qualquer inovação que surge provoca mudanças inesperadas em diversos setores da sociedade, cria novos negócios e até mesmo muda hábitos do cotidiano. Neste contexto as empresas que não conseguirem entender as mudanças e se apegarem aos seus modelos já tradicionais de negócio, usando as armas que conhecem e ignorando as novas armas, estarão fadadas ao insucesso.

As empresas precisarão ser resilientes de tal forma que possam se ajustar e adaptar, com a velocidade requerida para um cenário de incertezas e de mudanças rápidas. Para isso, significa tornarem-se proativas neste ambiente volátil, complexo, incerto, ambíguo e veloz. O retorno e a manutenção de suas atividades dentro do segmento produtivo estarão condicionados a sua capacidade de adaptar-se adequadamente a este cenário nebuloso.

\section{Considerações finais}

A eclosão da pandemia e a paralisação da economia foi uma ação sem precedentes. O mundo já conviveu, em épocas passadas, com pandemias, mas em nenhuma delas com esses resultados. A economia altamente globalizada e interdependente se viu diante de um "blackout" sem precedentes. Por mais que alguns setores se recuperem rápido, o efeito global continuará sendo crítico, com a maioria dos setores e países se recuperando lentamente, já que a atividade econômica vai demorar algum tempo para se normalizar.

Diante dessa situação a retomada econômica é uma incerteza, pois nunca aconteceu de termos um desligamento global como desta vez. A parada brusca da economia e atitudes restritivas à movimentação de pessoas e produtos exigiu mudanças de hábitos e costumes

Conceitos considerados tradicionais e arraigados dentro do mundo corporativo estão sendo repensados e passando por mudanças estruturais no 
enfrentamento da situação. Pensadores e estudiosos estão tentando conhecer as consequências pós pandemia para a economia mundial. Mesmo com a pandemia cessando existirão consequências e elas deixarão marcas, seja pelas atitudes e decisões tomadas ou por outro lado, por menosprezo ou repudio ao fator mudança.

O certo é que com a utilização de um ambiente remoto, através das tecnologias, os clientes serão protagonistas do processo, permitindo que ele interaja com a empresa e expresse opiniões que poderão ser utilizadas como propostas de melhorias. Com isso os apelos de marketing passam a ser mais diretos, com as empresas oferecendo produtos, direcionados a um segmento ou não, a qualquer lugar do planeta.

\section{Referências}

DOMINGUES, Diana (Org.). A arte no século XXI: a humanização das tecnologias. São Paulo: UNESP, 1997.

DRUCKER, Peter; Administrando para o Futuro, 1992, Ed. Pioneira

KOTLER, Philip; ARMSTRONG, Gary. Principios de Marketing. Tradução de Arlete Simille Marques, Sabrina Sairo . 9. Ed. São Paulo: Pearson Prentice Hall, 2003.

LUCAS Jr, Henry C..Tecnologia da informação. Rio de Janeiro: LTC, 2006.

MICELI, André, Artigo Tendências de Marketing e Tecnologia 2020: humanidade redefinida e es novos negócios"https://static.poder360.com.br/2020/04/estudo-fgv-tendencias.pdf

MORAES, Wallace G, Dilemas do Administrador, Ed. Ixtlan, 2012, SP

OLIVEIRA, Bruno de; Crie seu Mercado no Mundo Digital - (2018), Editora: Gente, São Paulo

POLO, Fernando e Polo Juan Luís - \#Socialholic: Tudo o Que Você Precisa Saber Sobre Marketing nas Mídias Sociais 2015, Editora Senac, São Paulo

TAURION, Cezar, O Primeiro Passo: A Transformação Digital como base para os negócios Pós-Digitais no século 21, 2016, eBook Kindle

TORRES, Cláudio. A bíblia do marketing digital. $1^{\underline{a}}$ ed. São Paulo: Novatec, 2009. 